Annales Geophysicae (2002) 20: 1863-1868 (C) European Geosciences Union 2002

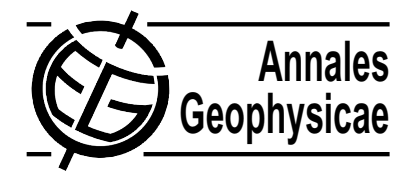

\title{
First observation of one noctilucent cloud by a twin lidar in two different directions
}

\author{
G. Baumgarten ${ }^{1}$, F.-J. Lübken ${ }^{1}$, and K. H. Fricke ${ }^{2}$ \\ ${ }^{1}$ Leibniz-Institut für Atmosphärenphysik, Kühlungsborn, Germany \\ ${ }^{2}$ Physikalisches Institut der Universität Bonn, Bonn, Germany
}

Received: 10 January 2002 - Revised: 17 April 2002 - Accepted: 19 April 2002

\begin{abstract}
In the early morning hours of 14 July 1999, a noctilucent cloud (NLC) was observed simultaneously by the two branches of a twin lidar system located at the ALOMAR observatory in northern Norway $\left(69^{\circ} \mathrm{N}\right)$. The telescopes of the two lidars were pointing vertical $\left(\mathrm{L}_{\perp}\right)$ and off the zenith by $30^{\circ}\left(\mathrm{L}_{30^{\circ}}\right)$. The two lidars detected an enhancement in the altitude profile of backscattered light (relative to the molecular background) for more than $5 \mathrm{~h}$, starting approximately at 01:00 UT. These measurements constitute the detection of one NLC by two lidars under different directions and allow for a detailed study of the morphology of the NLC layer. A cross-correlation analysis of the NLC signals demonstrates that the main structures seen by both lidars are practically identical. This implies that a temporal evolution of the microphysics within the NLC during its drift from one lidar beam to the other is negligible. From the time delay of the NLC structures, a drift velocity of $55-65 \mathrm{~m} / \mathrm{s}$ is derived which agrees nicely with radar wind measurements. During the observation period, the mean NLC altitude decreases by $\sim 0.5 \mathrm{~km} / \mathrm{h}(=14 \mathrm{~cm} / \mathrm{s})$ at both observation volumes. Furthermore, the NLC is consistently observed approximately $500 \mathrm{~m}$ lower in altitude at $\mathrm{L}_{30^{\circ}}$ compared to $\mathrm{L}_{\perp}$. Supplementing these data by observations from rocket-borne and groundbased instruments, we show that the general downward progression of the NLC layer through the night, as seen by both lidars, is caused by a combination of particle sedimentation by $4-5 \mathrm{~cm} / \mathrm{s}$ and a downward directed vertical wind by $9-10 \mathrm{~cm} / \mathrm{s}$, whereas a tilt of the layer in drift direction can be excluded.
\end{abstract}

Key words. Atmospheric composition and structure (cloud physics and chemistry; aerosols and particles) Meteorology and atmospheric dynamics (middle atmosphere dynamics)

\section{Introduction}

Noctilucent clouds (NLC) have been observed for more than 100 years in the upper summer mesosphere at polar and mid-

Correspondence to: F.-J. Lübken (luebken@iap-kborn.de) latitudes. They have attracted increasing attention in recent years when it became clear that their occurrence frequency has increased (Gadsden, 1998), which is possibly related to the long-term anthropogenic influences in the atmosphere (Thomas et al., 1989). It was speculated in the literature that this increase is caused by a temperature decrease that enhances the chance for ice particles to nucleate and grow. A recent study has shown, however, that there is no significant temperature change in the polar mesosphere, which leaves the question about the increase in the occurrence frequency unanswered (Lübken, 2000). It is obviously important to understand in detail the physical processes that create NLCs, including their relationship to the background conditions, such as temperature and water vapor concentration. The experimental investigation of NLCs has significantly improved since they where detected by lidars in twilight (Hansen et al., 1989), which is nowadays possible even in full daylight (von Zahn et al., 1998).

In this paper, we report on an important extension of this technique, namely the simultaneous observation of one NLC by a twin lidar system, where one telescope points vertically $\left(\mathrm{L}_{\perp}\right)$ and the second is tilted off the zenith by $30^{\circ}$ towards the northwest $\left(\mathrm{L}_{30^{\circ}}\right)$. As will be shown, this technique allows one to study horizontal variations in the NLC and to distinguish unambiguously between temporal and spatial variations in the cloud.

\section{Instrumentation and observations}

The ALOMAR Rayleigh/Mie/Raman lidar is a twin lidar system for measuring the backscattering of molecules and aerosols in the middle atmosphere (von Zahn et al., 2000). It is equipped with two transmitting Nd:YAG lasers and two receiving telescopes $(\oslash=1.8 \mathrm{~m})$ that collect the backscattered light. The light is guided through fibers to a single detection unit that records the backscattered light of the alternately emitting lasers. Both telescopes can be tilted independently up to $30^{\circ}$ off the zenith. The range of azimuths is restricted to $90^{\circ}$ between north and west for the northwest pointing 


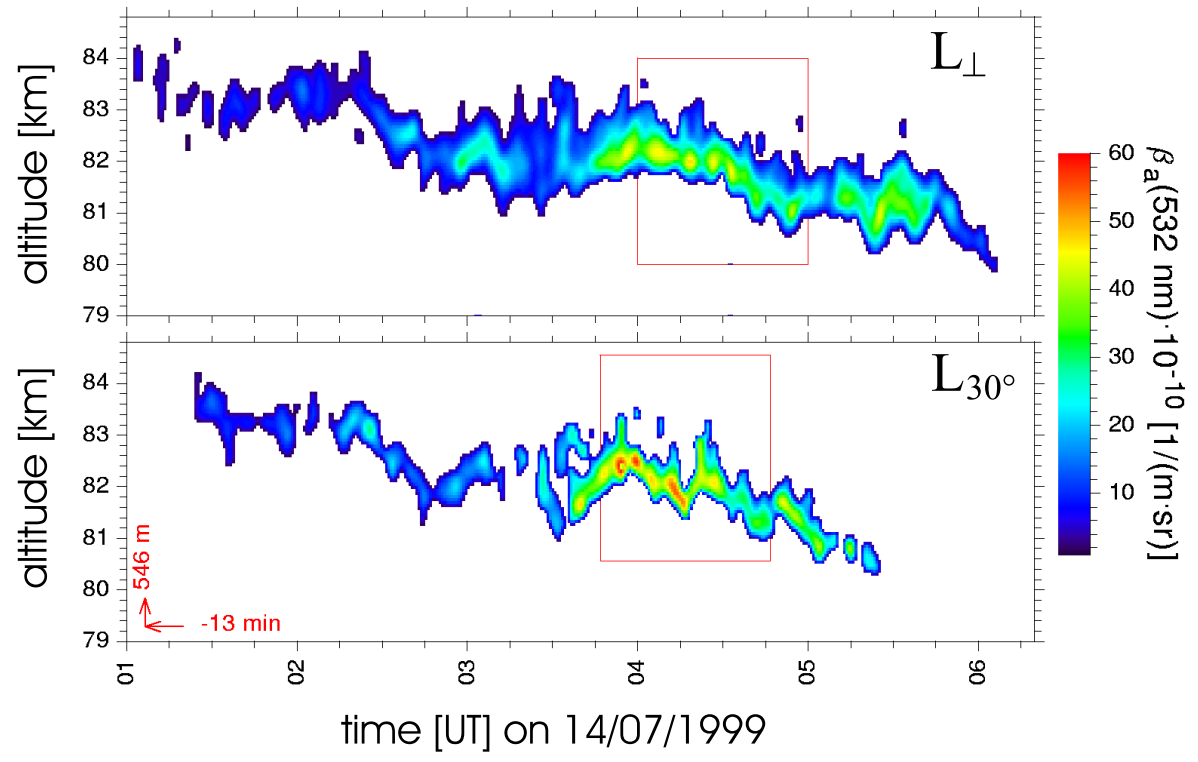

Fig. 1. Aerosol backscatter coefficients on 14 July 1999 for a lidar sounding in the vertical (upper panel) and a second lidar beam pointing off zenith by $30^{\circ}$ towards the northwest (lower panel). At $82 \mathrm{~km}$ the horizontal distance between the two lidar beams is $47.5 \mathrm{~km}$. The observations in the lower panel have been shifted in time by $-13 \mathrm{~min}$ and in altitude by $+550 \mathrm{~m}$, to obtain the maximum cross-correlation coefficient in the time/altitude region marked by the red rectangle in the upper panel. telescope (NWT), and between south and east for the southeast pointing telescope (SET). On 14 July 1999, the lidar was set up to measure towards zenith with the SET $\left(\mathrm{L}_{\perp}\right)$ while the NWT $\left(\mathrm{L}_{30^{\circ}}\right)$ was pointing $30^{\circ}$ off the zenith. The azimuth of $\mathrm{L}_{30^{\circ}}$ was set to $331^{\circ}$ to perform measurements at NLC altitudes in a common volume with a sounding rocket (DROPPS-2) launched on this day at 03:29 UT (Goldberg et al., 2001). At the altitude of the NLC $(\sim 82 \mathrm{~km})$, the atmospheric volumes measured by $\mathrm{L}_{\perp}$ and $\mathrm{L}_{30^{\circ}}$, respectively, were horizontally separated by $\sim 47.5 \mathrm{~km}$.

The lidar records the photons backscattered from air molecules and from aerosols at altitudes between approximately $15 \mathrm{~km}$ and $90 \mathrm{~km}$. The raw data (photon counts vs. altitude $z$ ) are converted to backscatter signals $S(z)$ by subtracting the sum of solar background and thermionic emission of the detectors, which is measured for each data set. From the backscatter signals of each lidar system, we calculate the backscatter ratios $R(z)$ :

$R(z)=\frac{S(z)}{S_{\mathrm{m}}(z)}=\frac{\beta_{m}(z)+\beta_{N L C}(z)}{\beta_{m}(z)}$,

where $S_{m}(z)$ is the backscattered signal from molecules, and $\beta_{m}(z)$ and $\beta_{N L C}(z)$ are the volume backscatter coefficients for air molecules and NLC particles, respectively. The volume backscatter coefficient for NLC particles is defined as:

$\beta_{N L C}(z)=\left.n_{N L C} \cdot \frac{d \sigma\left(180^{\circ}\right)}{d \Omega}\right|_{N L C}$,

where $\mathrm{n}_{N L C}$ is the number density of NLC particles and $\left.\frac{d \sigma\left(180^{\circ}\right)}{d \Omega}\right|_{N L C}$ is the effective cross section for backscattering by the NLC particle size distribution. An expression analogous to Eq. (2) applies for scattering on air molecules $\left(\beta_{m}\right)$. To facilitate comparison of observations made by the two lidars, we use the backscatter coefficient rather than the backscatter ratios, since the value of the latter depends on the background molecular density $\left(R \propto 1 / n_{m}\right.$ if $\left.\beta_{N L C} \gg \beta_{m}\right)$, and, thus, on the altitude of the NLC, even if the total amount and size of the NLC particles are identical at different altitudes. In practice, the backscatter coefficient is calculated from the backscatter ratios and the molecular backscatter coefficient by:

$\beta_{N L C}(z)=(R(z)-1) \cdot \beta_{m}(z)$.

The molecular backscatter coefficient $\beta_{m}(z)$ is derived as follows: at $z=35 \mathrm{~km}$ the backscatter signal $S(z)$ is normalized to the molecular backscatter signal $S_{m} \propto \beta_{m}$, which is calculated from the air densities taken from a tabulated data set. This data set is a combination of the relative densities measured by the lidar $(z<55 \mathrm{~km})$ normalized at $z=55 \mathrm{~km}$ to the absolute densities of Lübken (1999) which are used for altitudes above $55 \mathrm{~km}$. This procedure eliminates instrumental effects, for example, an insufficient alignment of the laser beam to the field of view of the telescope that has a diameter of $\sim 18 \mathrm{~m}$ at $100 \mathrm{~km}$ distance (Baumgarten, 2001).

We have averaged the backscattered signal $S(z)$ which consists of echoes from 5000 laser shots that correspond to a temporal resolution of roughly $3 \mathrm{~min}$. The range resolution is $150 \mathrm{~m}$. When determining the NLC altitude in the tilted system $\mathrm{L}_{30^{\circ}}$, we take the Earth's surface curvature into account which increases the derived altitude in $\mathrm{L}_{30^{\circ}}$ compared to $\mathrm{L}_{\perp}$ by $\Delta z \sim 170 \mathrm{~m}$. Sensitivity studies have shown that errors in altitude calculation by improper pointing of the telescope $(\Delta z \sim 10 \mathrm{~m})$ and the refraction of the light by the vertical gradient of the refractive index in air, due to the decrease in the air density $(\Delta z \sim 7 \mathrm{~m}$ ), can be neglected (Baumgarten, 2001).

The temporal evolution of the backscatter coefficients is shown in Fig. 1 for $\mathrm{L}_{\perp}$ (upper panel) and $\mathrm{L}_{30^{\circ}}$ (lower panel). Changes within the NLC can be generated by Eq. (1) tempo- 


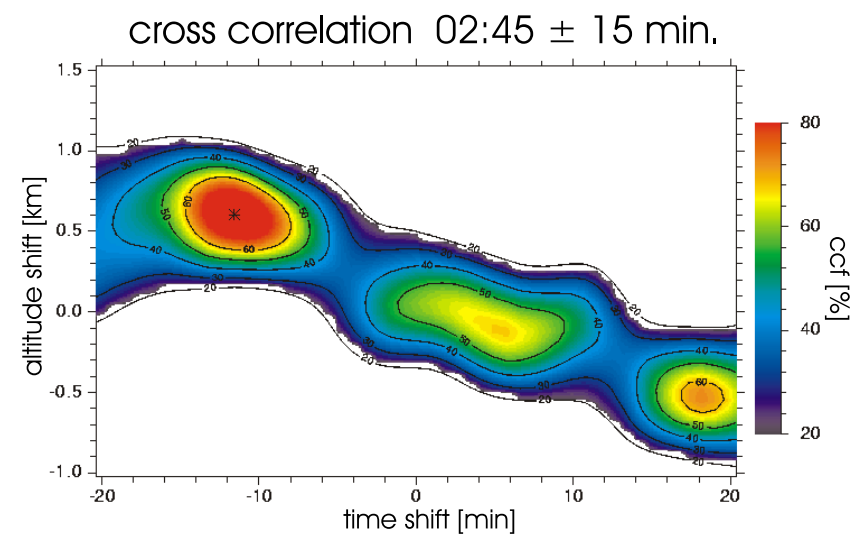

Fig. 2. Cross-correlation function for the time range of $02: 30$ to 03:00 UT. The total maximum at $\sim 600 \mathrm{~m}$ and $-12 \mathrm{~min}$ indicates that the NLC layer at $\mathrm{L}_{30^{\circ}}$ is observed later and at a lower altitude compared to $L_{\perp}$. The second and third maximum at +6 and +18 min indicates that there are periodic structures in the NLC with a period of $12-18 \mathrm{~min}$.

ral variations of the NLC, e.g. by growth or evaporation of particles, and/or Eq. (2) by the horizontal drift of a horizontally inhomogeneous NLC through the lidar beam. To separate temporal from spatial variations within the NLC, we search for common patterns in the observations of $\mathrm{L}_{\perp}$ and $\mathrm{L}_{30^{\circ}}$. If, for example, $\mathrm{L}_{30^{\circ}}$ observes a pattern that has been observed earlier in $\mathrm{L}_{\perp}$, then we know that this pattern has been generated by the horizontal drift of the NLC from $\mathrm{L}_{\perp}$ to $\mathrm{L}_{30^{\circ}}$. An example of a pattern observed by both lidars is the drop of the NLC altitude around 02:30 UT. Another example is the variation of strong (red in Fig. 1) and weak (blue in Fig. 1) backscattering by the NLC between 04:00 and 05:00 UT. To better identify common patterns in the NLC observations, we calculate the two-dimensional normalized cross-correlation function $c c f(\Delta t, \Delta z)$ as a function of time $(\Delta t)$ and altitude $(\Delta z)$ shift (Jenkins and Watts, 1968). If both lidar systems observe the same patches, then the normalization of $c c f$ gives $c c f=+100 \%$ and $c c f=-100 \%$ if both observations are anti-correlated. In practice, the maximum correlation will not reach $100 \%$ due to different efficiencies and data noise in both lidar systems. To take the system efficiency into account when comparing the lidar observations, we neglect those backscatter coefficients that are weaker than the measurement error $\left(\beta_{N L C}<\Delta \beta_{N L C}\right)$. Tests have shown that the maximum achievable correlation of this twin lidar system is $90 \%$ if both systems observe a NLC in a common volume (Baumgarten, 2001). Due to the different observation geometry of $\mathrm{L}_{\perp}$ and $\mathrm{L}_{30^{\circ}}$, the maximum achievable correlation is somewhat lower. This behavior is obvious in Fig. 1, where the NLC appears to be narrower in $\mathrm{L}_{30^{\circ}}$ than in $\mathrm{L}_{\perp}$, since the weaker backscattering at the edges of the NLC are not significant in $\mathrm{L}_{30^{\circ}}$. The lidar pointing off the zenith is less efficient due to the longer optical path through the troposphere and additional instrumental effects. Taking these effects into account, we expect a maximum $c c f$ on the

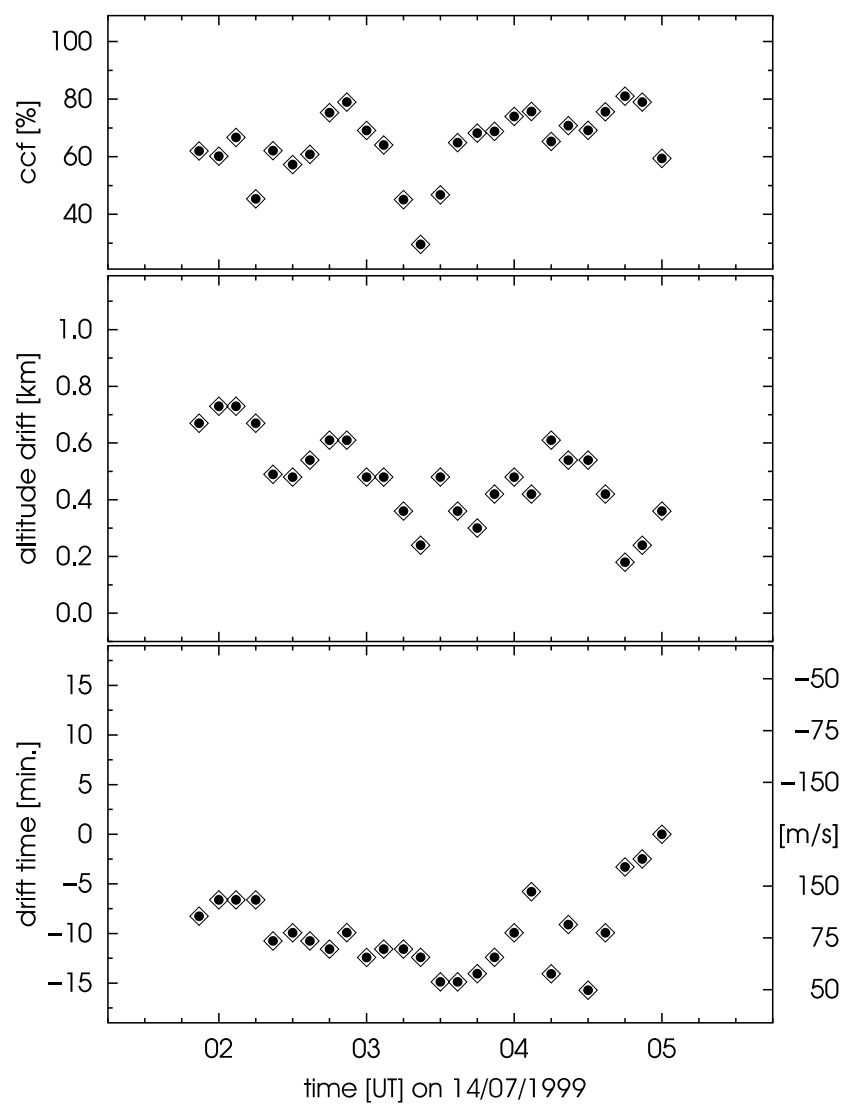

Fig. 3. Maximum of the cross-correlation function for successive time intervals of $30 \mathrm{~min}$ each (top pannel). The middle panel shows the corresponding altitude difference and the lower panel shows drift time and the derived drift speed (right scale) of a pattern along the baseline of the two volumes.

order of $\sim 80 \%$. An example is shown in Fig. 2, where the common pattern is identified by the maximum $c c f$ value at $\Delta t=-12 \mathrm{~min}$ and $\Delta z=600 \mathrm{~m}$.

The results of the cross-correlation method are shown in Fig. 3, where the $c c f$ of successive time frames with a length of $30 \mathrm{~min}$ each are shown. The fact that the $c c f$ is very high $(60-80 \%)$ leads to the conclusion that the temporal variations of the NLCs are generated by horizontal drift rather than being caused by changes in particle number densities and size due to growth or evaporation.

During most of the time, unique NLC patterns appear $\sim 12$ min earlier in $\mathrm{L}_{\perp}$ than in $\mathrm{L}_{30^{\circ}}$, and the NLC is observed approximately $550 \mathrm{~m}$ higher at $\mathrm{L}_{\perp}$ compared to $\mathrm{L}_{30^{\circ}}$ (see Fig. 3, middle panel). From the drift time of a NLC pattern from $\mathrm{L}_{\perp}$ to $\mathrm{L}_{30^{\circ}}$, we calculate the drift speed, assuming that the NLC drifts along the baseline of the measurement volumes that correspond to a drift towards northwest, corresponding to a drift direction of $151^{\circ}$ (meteorological convention). The results are shown in the lower panel of Fig. 3. Independent wind measurements were performed on this day by the ALOMAR MF radar after 04:00 UT which show a wind speed $v_{R} \sim 40-50 \mathrm{~m} / \mathrm{s}$ from $110-120^{\circ}$ at NLC altitudes (W. Singer, private communication). The measure- 
ments of the ALOMAR MF radar show that the actual horizontal wind was not blowing along the baseline connecting both lidar measurement volumes, but rather at an angle of $\alpha \sim 30^{\circ}$ with respect to this line. It should be pointed out that the observed northward directed atmospheric motion at the altitude of the NLC is rare. Typically, the wind at NLC altitudes is westward to southwestward directed $(30-40 \mathrm{~m} / \mathrm{s}$, 60-90 Lübken et al., 1990; Hoffmann et al., 1997).

\section{Discussion}

The cross-correlation coefficient of the NLCs seen by the two lidars is larger than $60 \%$ most of the time. No significant differences are observed either in structure or in absolute magnitude, which suggests that both lidars see the same NLC. Temporal variations caused by growth or evaporation during the drift period are negligible. Instead, we observe a drifting cloud. The cross-correlation analysis presented in Figs. 2 and 3 shows that the NLC arrives at $\mathrm{L}_{30^{\circ}}$ approximately 12 14 min after it was detected at $\mathrm{L}_{\perp}$, which corresponds to a drift speed of $v_{D} \sim 55-65 \mathrm{~m} / \mathrm{s}$. If we assume that the structures are homogeneous perpendicular to the drift direction of the cloud, then this drift speed corresponds to a horizontal wind speed $v_{L}$ of approximately $v_{L}=v_{D} \cdot \cos \alpha \sim 60 \cdot \cos 30$ $=52 \mathrm{~m} / \mathrm{s}$, where $\alpha$ is the angle between the direction of the wind and the baseline of both lidar measurements. The wind speed derived from the lidar measurements is in nice agreement with the MF radar wind measurements that show a wind speed of $v_{R} \sim 40-50 \mathrm{~m} / \mathrm{s}$. Due to technical reasons, the wind measurements with the MF radar commenced approx. two hours after the beginning of the lidar observations. This prevents comparisons of the drift measurements by the lidar and the radar wind measurements for the entire observation period.

During the five-hour observation period, the mean NLC altitude at both places decreases by approximately $0.5 \mathrm{~km} / \mathrm{h}$ $(=14 \mathrm{~cm} / \mathrm{s})$. We can speculate that this apparent downward progression is caused by a layer that is tilted upwards (looking along the drift direction) and thereby causes the cloud height to decrease when the layer moves through the lidar beams. However, in this case, the downstream lidar $\mathrm{L}_{30^{\circ}}$ should see the NLC at higher altitudes compared to $\mathrm{L}_{\perp}$, contrary to the observations. We conclude that the NLC layer is not significantly tilted and that the NLC particles must actually have moved down. The downward motion of the NLC by $\sim 14 \mathrm{~cm} / \mathrm{s}$ can be caused by sedimentation or by a downward directed wind, or by a combination of both. We will discuss both mechanisms separately with respect to their physical relevance, by taking into account supportive measurements.

Assuming for a moment zero vertical winds, the fall velocity of $14 \mathrm{~cm} / \mathrm{s}$ corresponds to particles with a radius of $\mathrm{r}_{a} \sim 100-150 \mathrm{~nm}$, which is rather large for NLC particles but can certainly not be excluded (Gadsden and Schröder, 1989; von Cossart et al., 1999). Assuming a log-normal particle size distribution, we deduce from the typical backscatter coefficient $\beta_{N L C}=3 \cdot 10^{-9} / \mathrm{m} \cdot \mathrm{sr}$, corresponding to a backscatter ratio of $\mathrm{R}=120$ the median particle radius. We achieve radii of $r \sim 20-80 \mathrm{~nm}$ depending on the unknown particle number densities (presumably between 10 and $10000 / \mathrm{cm}^{3}$ ) and the width of the particle size distribution $(\sigma=1.0-1.4)$. The range of radii mentioned above is compatible with the ratio of the NLC signals at the two laser wavelengths ( 355 and $532 \mathrm{~nm}$ ), which is $\beta_{355} / \beta_{532} \sim 2.5-5.5$. Independent information on the particle size comes from the photometer measurements on board the DROPPS sounding rocket payload which was launched on the same day at 03:30 UT (Gumbel et al., 2001). Analysis of the scattering phase functions gave $r=40-50 \mathrm{~nm}$ and $N=200-3000 / \mathrm{cm}^{3}$. This, in turn, corresponds to sedimentation velocities of $4-5 \mathrm{~cm} / \mathrm{s}$, thus, significantly smaller than the apparent downward progression of $14 \mathrm{~cm} / \mathrm{s}$ mentioned above and (if representative for the entire observation period) implies mean downward directed vertical winds of $9-10 \mathrm{~cm} / \mathrm{s}$. Such a wind corresponds to an adiabatic heating that can be calculated from:

$$
\frac{d T}{d t}=v_{z} \cdot \Gamma=-0.35 \cdot v_{z}\left[\frac{K}{h}\right] \quad\left(v_{z} \text { in } \mathrm{cm} / \mathrm{s}\right),
$$

where $\Gamma=-9.8 \mathrm{~K} / \mathrm{km}$ is the adiabatic lapse rate. For the vertical wind speeds $\left(v_{z}\right)$ mentioned above, we would, therefore, expect an adiabatic heating of $3-4 \mathrm{~K} / \mathrm{h}$. There have been simultaneous temperature measurements by falling spheres during the NLC observation (Schmidlin and Schauer, 2001). We concentrate on the flights labeled MDFS15 and MDFS17 that were launched at 04:10 and 05:04 UT, respectively. Indeed, the temperatures in the NLC layer are larger during MDFS17 by approximately $4.5-5 \mathrm{~K}$ compared to MDFS 15 . This temperature increase is compatible with the heating scenario outlined above. We conclude that the general downward progression of the NLC layer seen by both lidars is caused by a combination of particle sedimentation and downward vertical winds, whereas a tilt of the layer in drift direction is excluded. We note that this downward directed wind is opposite to the mean wind direction, even if the diurnal tide is taken into account (Berger and von Zahn, 2002).

At $\mathrm{L}_{30^{\circ}}$, the NLC layer is observed to be consistently lower in altitude by 400 to $600 \mathrm{~m}$ compared to $\mathrm{L}_{\perp}$. This observation is in nice agreement with the photometer measurements on DROPPS rocket payload mentioned above, which showed the NLC layer approximately $1.6 \mathrm{~km}$ higher on upleg compared to downleg. This altitude difference corresponds to a tilt of the layer along the baseline of both NLC interceptions of $\sim 0.8^{\circ}$ (horizontal distance between upleg and downleg: $\sim 111 \mathrm{~km}$; Gumbel et al., 2001). The lidar NLC altitude difference corresponds to a layer tilt of $0.5-0.7^{\circ}$ or, alternatively, to a downward motion of $70 \mathrm{~cm} / \mathrm{s}$, thus, significantly larger compared to the general downward motion of the NLC particles discussed above. We have already noted that a downward tilt of the layer in drift direction would disagree with the apparent 'sinking' of the NLC layers observed by the twin lidar. Furthermore, we can exclude that the $500 \mathrm{~m}$ altitude difference is caused by locally restricted sedimentation or by winds. A sedimentation by $70 \mathrm{~cm} / \mathrm{s}$ would require particles with $r \sim 700 \mathrm{~nm}$, thus, much larger than the radii 


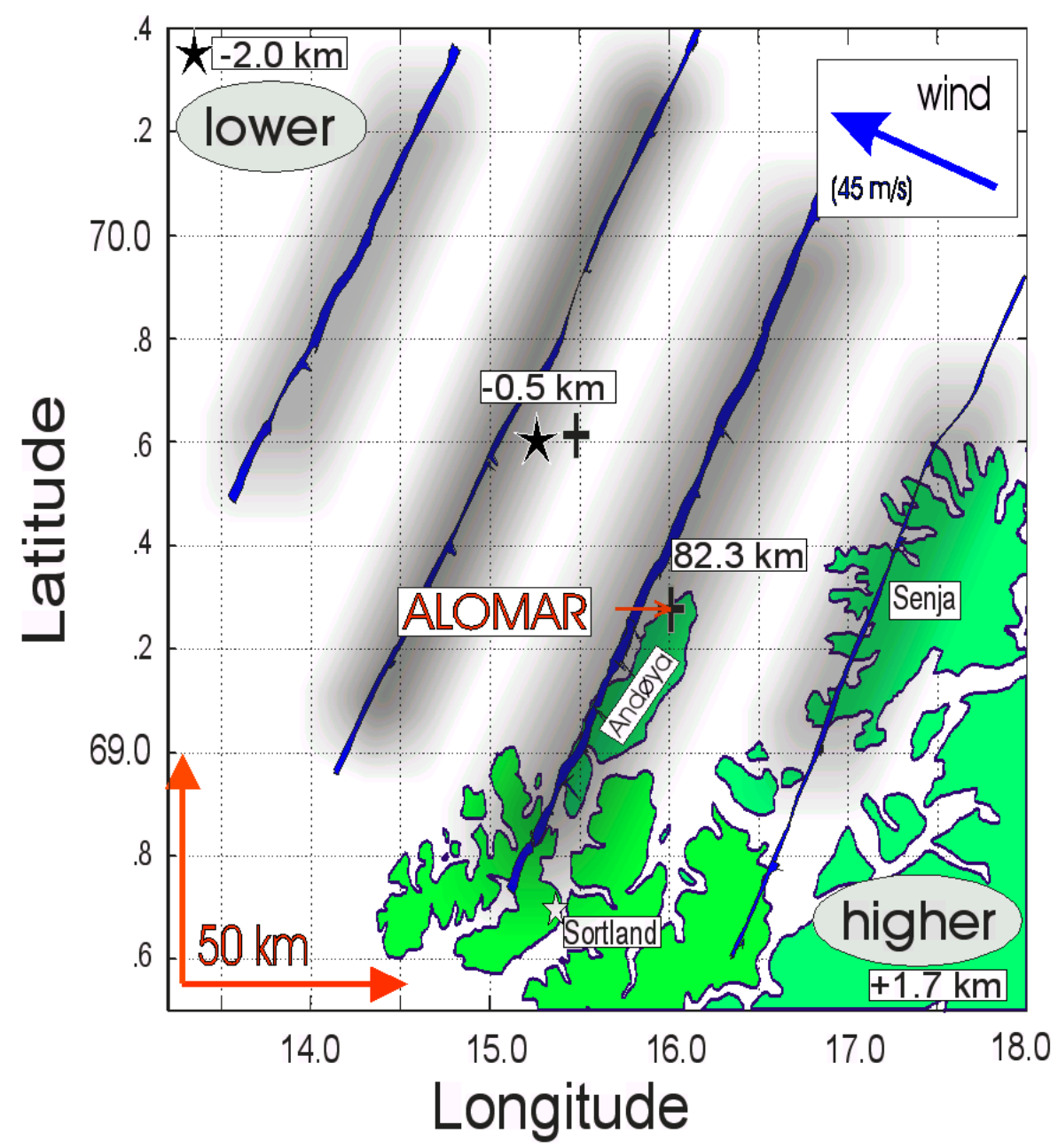

Fig. 4. Sketch of the NLC layer detected over ALOMAR on 14 July 1999. The ground position of the volumes at $82 \mathrm{~km}$ monitored by the twin lidar pointing vertically and off zenith by $30^{\circ}$, respectively, are marked by crosses. The positions where the DROPPS sounding rocket payload detected the NLC on upleg and downleg, respectively, are marked by stars. deduced above. Vertical winds of similar magnitude would heat the atmosphere by $\sim 25 \mathrm{~K} / \mathrm{h}$, which would cause a partial evaporation and shrinking of the ice particles by $\sim 10 \mathrm{~nm}$ on their way from $L_{\perp}$ to $L_{30^{\circ}}$. This would imply weaker NLC at $\mathrm{L}_{30^{\circ}}$ compared to $\mathrm{L}_{\perp}$ (contrary to observations), and the NLC should have disappeared before it arrives at the downleg part of the DROPPS flight (where it was observed, as discussed above). The only explanation left is a tilt of the NLC layer by $\sim 1^{\circ}$ perpendicular to the mean drift direction, so that the NLC appears persistently to be $\sim 500 \mathrm{~m}$ lower at $\mathrm{L}_{30}$ 。 compared to $\mathrm{L}_{\perp}$.

The cross-correlation analysis shows that a similar pattern is observed repeatedly in the NLC. For example, the layer observed at $\mathrm{L}_{\perp}$ in the period 2:30-3:00 UT shows quasiperiodic variations with a period of $12-18 \mathrm{~min}$ (Fig. 2). The cross-correlation analysis shows further that these structures observed at $\mathrm{L}_{\perp}$ were observed 13 min later at $\mathrm{L}_{30^{\circ}}$. Basically no changes were found in the cloud from one observation volume to the other, although the lidar $\mathrm{L}_{\perp}$ and $\mathrm{L}_{30^{\circ}}$. are not observing the same patch of the NLC, since the NLC drifts with an angle $\alpha=30^{\circ}$ off the baseline that connects both volumes observed by the twin lidar. The only expla- nation for the observation of common patterns in both lidar systems is that there are constant structures in the NLC that are aligned more or less perpendicular to the drift direction. Such structures are often seen in visual observations of NLC and are called bands (WMO, 1970). From the time period of $12-18 \mathrm{~min}$, we calculate that the separation of the bands is $30-50 \mathrm{~km}$, taking the wind speed of $40-50 \mathrm{~m} / \mathrm{s}$ into account. The distance of the volumes of measurements perpendicular to the drift direction of the NLC is $20-30 \mathrm{~km}$, which implies that the bands are at least that long. The resulting topology of the NLC observations and the wind direction is sketched in Fig. 4. The spatial variations observed in the NLC appearance can presumably be introduced by variations in the background atmosphere (e.g. temperatures, water vapor) induced by gravity waves.

\section{Conclusion and outlook}

The twin lidar observations allow for the first time to distinguish among temporal and spatial variations in the cloud. From the simultaneous observation of a NLC at two locations with a horizontal distance of $47 \mathrm{~km}$, we have found no sig- 
nificant differences in cloud properties, which implies that the cloud has not undergone microphysical changes during the drift time of $\sim 13 \mathrm{~min}$. The observations and the conclusions drawn from the result presented above are consistent with current models of NLCs.

In the future, we intend to further exploit the experimental capabilities of the twin lidar system and the steerability of the telescopes to investigate the horizontal structure of NLCs and their temporal variation. In cooperation with the ALOMAR ozone lidar, we are able to observe the NLC in three different volumes, which gives us the opportunity to determine the orientation of an NLC layer in three dimensions, where the measurement volumes are separated by up to $\sim 100 \mathrm{~km}$. These measurements will be combined with microphysical and hemispherical models of NLC generation that have been used recently to elucidate the temporal and spatial development of ice particles in the polar upper mesosphere (Berger and von Zahn, 2002; Rapp et al., 2001). From this we hope to gain further insight into the physical processes leading to NLCs and the interaction with the dynamical and thermal state of the atmosphere.

Acknowledgement. The excellent work by Götz von Cossart, Jens Fiedler, Ulf von Zahn and Reidar Lyngra is gratefully acknowledged. This project was supported by the European commission through the ALOMAR large scale facility (LSF). The falling sphere rocket launches within the MIDAS/DROPPS campaign were supported by the Bundesministerium für Bildung, Wissenschaft, Forschung und Technologie, Bonn, under grant number 50 OE 9802 .

Topical Editor D. Murtagh thanks two referees for their help in evaluating this paper.

\section{References}

Baumgarten, G.: Leuchtende Nachtwolken an der polaren Sommermesopause: Untersuchungen mit dem ALOMAR Rayleigh/Mie/Raman Lidar, Ph.D. thesis, Universität Bonn, BONN-IR-2001-10, 2001.

Berger, U. and von Zahn, U.: Icy particles in the summer mesopause region: 3-dim modelling of their environment and 2-dim modelling of their transport, J. Geophys. Res., in print, 2002.

Gadsden, M.: The northwest Europe data on noctilucent clouds: A survey, J. Atmos. Sol.-Terr. Phys., 60, 1163-1174, 1998.

Gadsden, M. and Schröder, W.: Noctilucent Clouds, SpringerVerlag, New York, 1989.

Goldberg, R. A., Pfaff, R. F., Holzworth, R. H., Schmidlin, F. J., Voss, H. D., Tuzzolino, A. J., Croskey, C. L., Mitchell, J. D.,
Friedrich, M., Murtagh, D., Witt, G., Gumbel, J., von Zahn, U., Singer, W., and Hoppe, U.-P.: DROPPS: A study of the polar mesosphere with rocket, radar and lidar, Geophys. Res. Lett., 28, 1407-1410, 2001.

Gumbel, J., Stegman, J., Murtagh, D., and Witt, G.: Scattering phase functions and particle sizes in noctilucent clouds, Geophys. Res. Lett., 28, 1415-1418, 2001.

Hansen, G., Serwazi, M., and von Zahn, U.: First detection of a noctilucent cloud by lidar, Geophys. Res. Lett., 16, 1445-1448, 1989.

Hoffmann, P., Singer, W., Keuer, D., Bremer, J., and Rüster, R.: Mean diurnal variations of PMSE as measured with the ALOMAR Sousy radar during summer 1996, Proceedings of the 13th ESA Symposium on European Rocket and Balloon Programmes and Related Research, Öland, Sweden, 471-475, 1997.

Jenkins, G. M. and Watts, D. G.: Spectral Analysis and its Applications, Holden-Day, Oakland, California, 1968.

Lübken, F.-J.: Thermal structure of the Arctic summer mesosphere, J. Geophys. Res., 104, 9135-9149, 1999.

Lübken, F.-J.: Nearly zero temperature trend in the polar summer mesosphere, Geophys. Res. Lett., 27, 3603-3606, 2000.

Lübken, F.-J., von Zahn, U., Manson, A., Meek, C., Hoppe, U.P., Schmidlin, F. J., Stegman, J., Murtagh, D. P., Rüster, R., Schmidt, G., Widdel, H.-U., and Espy, P.: Mean state densities, temperatures and winds during the MAC/SINE and MAC/EPSILON campaigns, J. Atmos. Terr. Phys., 52, 955-970, 1990.

Rapp, M., Lübken, F.-J., Müllemann, A., Thomas, G. E., and Jensen, E. J.: Small scale temperature variations in the vicinity of NLC: Experimental and model results, J. Geophys. Res., 107, 10.1029/2001JW001241, in print, 2001.

Schmidlin, F. J. and Schauer, A.: Mesospheric clouds and the neutral atmosphere during the 1999 DROPPS/MIDAS campaign, Geophys. Res. Lett., 28, 1411-1414, 2001.

Thomas, G. E., Olivero, J. J., Jensen, E. J., Schröder, W., and Toon, O. B.: Relation between increasing methane and the presence of ice clouds at the mesopause, Nature, 338, 490-492, 1989.

von Cossart, G., Fiedler, J., and von Zahn, U.: Size distributions of NLC particles as determined from 3-color observations of NLC by ground-based lidar, Geophys. Res. Lett., 26, 1513-1516, 1999.

von Zahn, U., von Cossart, G., and Fiedler, J.: Tidal variations of noctilucent clouds measured at $69^{\circ} \mathrm{N}$ latitude by groundbased lidar, Geophys. Res. Lett., 25, 1289-1292, 1998.

von Zahn, U., von Cossart, G., Fiedler, J., Fricke, K. H., Nelke, G., Baumgarten, G., Rees, D., Hauchecorne, A., and Adolfsen, K. The ALOMAR Rayleigh/Mie/Raman lidar: Objectives, configuration, and performance, Ann. Geophys., 18, 815-833, 2000.

WMO, International noctilucent cloud manual, World Meteorological Organisation, No. 250, TP.138, 1970. 